\title{
ALFONSO X, EL REINO DE GRANADA Y LOS BANŪ AŠQĪLŪLA. ESTRATEGIAS POLÍTICAS DE DISOLUCIÓN \\ DURANTE LA SEGUNDA MITAD DEL SIGLO XIII
}

\author{
FRANCISCO GARCÍA FITZ \\ Universidad de Extremadura
}

La mayoría de las obras que se han dedicado a analizar el arte de la guerra en la Edad Media se han centrado exclusivamente en el análisis de la más o menos amplia panoplia de recursos bélicos que los dirigentes tuvieron a su disposición para la consecución de sus objetivos políticos. Así, el armamento, las tácticas, las estrategias, la logística, los sistemas de reclutamiento, la composición y organización de los ejércitos, las obligaciones militares, los mecanismos de financiación de las campañas o el valor personal, entre otros temas, han sido objeto de la atención de los especialistas como si de la interacción de todos aquellos factores militares pudiera desprenderse el conocimiento global de un conflicto dado y las claves de su resultado final, ignorándose, en cambio, la intervención y la transcendencia de otros mecanismos no estrictamente bélicos, pero capaces de determinar el curso de un enfrentamiento.

En este sentido, resulta sorprendente la nítida distinción que en muchas ocasiones se realiza entre la guerra y la política, entendidas como ámbitos de actuación perfectamente disociados. Parece que los historiadores del hecho bélico, apegados al campo de batalla, han evitado llevar a su terreno de estudio una de las conclusiones fundamentales que los tratadistas militares vienen repitiendo, al menos, desde el primer tercio del siglo XIX, y es que la guerra y la política forman una unidad sustancial desde el punto de vista estratégico. 
Como se sabe, fue el tratadista prusiano Karl von Clausewitz quien, poco después de las guerras napoleónicas, afirmó que la guerra no era otra cosa que "la continuación del intercambio político con una combinación de otros medios" 1 o que, en la más reciente traducción de este axioma propuesta por John Keegan, la guerra era "la continuación «de la relación política» (des politischen Verkehrs) «con la intrusión de otros medios» (mit Einmischung anderer Mittel)"2. Aunque la concepción que Clausewitz tenía de la estrategia implicaba sólo la consideración de los elementos militares envueltos en un conflicto ${ }^{3}$, aquella primera vinculación entre guerra y política tuvo como resultado que, poco después, las relaciones políticas llegaran a ser entendidas como una parte más de las estrategias de confrontación. Así, a mediados del siglo XIX, Jomini señalaba, al definir su concepto de arte de la guerra, que en el mismo se encuadraban cinco ramas de actividades puramente militares - la Estrategia, las Grandes Tácticas, la Logística, la Ingeniería y las Tácticas- a las que debía añadirse una sexta que, según él, hasta entonces no había sido reconocida como parte esencial de la guerra, y a la que denominó la "Diplomacia en su relación con la Guerra"4. Hoy en día, los teóricos de la guerra tienden a considerar que la estrategia no consiste únicamente en la utilización de las fuerzas militares para lograr metas políticas, sino en el empleo de todos los recursos posibles, incluyendo aquéllos que no son puramente bélicos, como las relaciones políticas o diplomáticas 5 .

Pero tampoco resulta de todo punto necesario la apoyatura de los grandes tratadistas militares para sostener algo que resulta obvio cuando uno se acerca al estudio de las fuentes medievales, y es que las relaciones políticas fueron utilizadas por los dirigentes como una herramienta más, junto a los instrumentos puramente militares, para alcanzar los objetivos propuestos o para imponer su voluntad a los adversarios.

\footnotetext{
'Karl von Clausewitz, De la guerra, Barcelona, 1976, pp. 320-321. El presente artículo se inserta en el proyecto de investigación PB96-1531 de la Dirección General de Enseñanza Superior sobre "Guerra y Frontera en la Edad Media Peninsular".

${ }^{2}$ John KEEGAN, Historia de la guerra, Barcelona, 1995, p. 21.

${ }^{3}$ Clausewitz entendía por estrategia el conjunto de actividades conducentes a la combinación de unos encuentros militares con otros para alcanzar la derrota del enemigo en el campo, $o p$. cit., pp. 120-121.

${ }^{4}$ Henri Antoine de Jomini, The Art of War, Londres, 1992, p. 13. 29.

${ }^{5}$ Así, por ejemplo, en André BEAufré, Introducción a la Estrategia, Madrid, 1965, pp. 28 -
} 
Cualesquiera que sean las justificaciones aducidas por los contemporáneos o las interpretaciones aportadas por los medievalistas, de lo que nadie duda es de que los reinos cristianos peninsulares mantuvieron, durante buena parte del período medieval, un objetivo político esencial frente a sus vecinos musulmanes: la ampliación del espacio dominado, la expansión territorial a costa de al-Andalus. Desde el punto de vista que aquí interesa, resulta irrelevante que aquella expansión respondiera a una deliberada voluntad por reconquistar un territorio, que fuera el reflejo de la confrontación entre dos formaciones económico-sociales, o que representara una de las formas de reproducción del sistema feudal, puesto que todos los supuestos anteriores implican un mismo objetivo: la anexión de los territorios ocupados por la población islámica.

Por supuesto, en la consecución de aquel objetivo se emplearon instrumentos estratégicos de carácter militar -operaciones de desgaste, guerra de asedios, confrontaciones campales $-{ }^{6}$, pero a veces las estrategias políticas jugaron un papel tan importante o más que las militares en el proceso de conquistas y anexiones territoriales. Los mecanismos fueron de diverso tipo, desde el establecimiento de alianzas supuestamente protectoras con éste o aquél poder musulmán, acuerdos que en realidad suponían un importante punzamiento de sus recursos económicos, hasta el apoyo a unos reinos islámicos frente a otros, en una dinámica que acababa debilitándolos a todos. Pues bien, una de estas herramientas utilizadas por los reinos cristianos frente ? sus vecinos de al-Andalus fue lo que podríamos denominar como "estrategia política de disolución", esto es, el establecimiento de una serie de pactos con sectores disidentes de un determinado reino o con gobernantes enfrentados a bandos rebeldes, en orden a fomentar un proceso de desestabilización interna que facilitara una posterior anexión territorial.

Durante la segunda mitad del siglo XIII se produjo una de estas situaciones que favorecía la intervención de los poderes cristianos en las crisis políticas de al-Andalus, y que Alfonso X intentó aprovechar para ampliar su dominio territorial sobre el reino nazarí de Granada. Nos referimos a la rebelión de los Banū Ašqīlūla en 1266 o 12677. Debe

\footnotetext{
${ }^{6}$ Francisco GARCía FITZ, Castilla y León frente al Islam. Estrategias de expansión y tácticas militares (siglos XI al XIII), Sevilla, 1998, passim.

${ }^{7}$ Las fuentes no son concluyentes a la hora de establecer una cronología cierta sobre la revuelta mudéjar y la guerra castellano-nazarí - acontecimientos en los que se inserta la rebelión-, de modo que los diversos autores que se han acercado al tema han propuesto fechas
} 
advertirse de antemano que el rey de Castilla no llegó a conseguir plenamente sus fines, pero tal vez en ningún otro caso como en éste los ejecutores de una "estrategia política de disolución" dejaron tan clara y expresamente plasmadas sus ideas en torno a los objetivos políticos, militares y territoriales que podían alcanzarse por esta vía, razón por la cual el ejemplo resulta perfectamente válido para el análisis de aquella herramienta estratégica.

Cuando Alfonso X se dispuso a apoyar a los sediciosos granadinos en contra de Muhammad I, la política de aprovechamiento y fomento de las querellas internas de los reinos musulmanes tenía a sus espaldas una tradición de dos siglos: en 1068, tras la muerte de al-Muzaffar, rey taifa de Badajoz, dos de sus hijos se disputaron la herencia paterna recurriendo respectivamente al apoyo de al-Mamūn de Toledo y de al-Mu'tamid de Sevilla. Pues bien, según una fuente contemporánea, Alfonso VI no se privó de participar en el botín que se avecinaba y obtuvo, no sabemos a instancias de quién, "toda la tierra musulmana que apeteció, y sus bienes y riquezas, recurriendo a sembrar cizaña entre los antagonistas"8. Más claro aún, aunque no sea éste el lugar para analizarla con detalle, la actividad política de este mismo monarca, tendente primero a afianzar en el trono a al-Qādir de Toledo contra todos aquéllos que se le enfrentaron entre 1075 y 1082, y después a apoyar a un bando político frente a otro entre 1082 y 1085, tuvo como consecuencia la ruina de las bases económicas del reino, la desarticulación de sus solidaridades internas, la permanente desestabilización, la anexión de importantes plazas como contrapartida al auxilio militar prestado a alguna de las partes -Zorita, Canturias y Canales, entre otras-, y la conquista final de la ciudad de Toledo". Tal como afirmara algún historiador

que oscilan entre 1265 y 1267. Véase, por ejemplo, Manuel GonZÁlez JiMÉnEZ, Alfonso X, 1252-1284, Palencia, 1993, p. 80; Rachel ARIÉ, L'Espagne Musulmane au temps des Nasrides (1232-1492), París, 1990, p. 66; Joseph F. O’Callaghan, El Rey Sabio. El reinado de Alfonso $X$ de Castilla, Sevilla, 1996, p. 233.

${ }^{8}$ Véase Ramón MenÉndez Pidal, La España del Cid, I, Madrid, 1956, pp. 166-167. El testimonio lo recogió Ibn al-Jatîb, citado y traducido en María Jesús VigUerA MOLINS et alii, Los reinos de taifas. Al-Andalus en el siglo XI, Madrid, 1994, p. 85

${ }^{9} \mathrm{ABd}$ AllāH, Memorias, en El Siglo XI en Ia persona. Las "Memorias" de Abd Alläh, último Rey Ziri de Granada, destronado por los almorávides (1090), trad., introd. y not. por E. Lévi-Provençal y Emilio García Gómez, Madrid, 1980, pp. 162-163; IBN AL-KaRDabūS, Historia de al-Andalus (Kitāb al-Iktifá'), est., trad. y not. de Felipe Maíllo Salgado, Madrid, 1993, pp. 100-106 (en lo sucesivo IBN AL-KARDABŪS, Historia de al-Andalus); Rodrigo JIMÉNEZ DE RADA, Historia de Rebus Hispanie, ed. Juan Fernández Valverde, Turnholti, 1987, Lib. VI, cap. XXII (en lo sucesivo HRH); Primera Crónica General de España, ed. Ramón Menéndez Pidal, Madrid, 1977, cap. 866 (en lo sucesivo PCG); E. LÉvi-PrOVENÇAL, Alphonse VI et la 
musulmán al referirse a una de las peticiones de auxilio de al-Qādir, "secretamente algo regocijaba a Alfonso: la discordia que tenía lugar entre los gobernantes de los musulmanes. Él ayudaba a éste contra éste y a aquél contra aquél, atrayéndose así sus riquezas con el vehemente deseo de que se debilitasen; entonces él obtendría la posesión de toda la Península"10.

Este tipo de estrategia política tuvo continuidad a lo largo del siglo XII, pero con matices variados en función de las circunstancias de cada momento. No obstante, no resulta preciso realizar un recuento de todas la ocasiones en que los reyes castellano-leoneses consiguieron un provecho territorial de coyunturas como las comentadas. En realidad, Alfonso X no necesitaba de una larga memoria histórica para comprender los mecanismos de funcionamiento de la estrategia de disolución, puesto que podía encontrar en las actuaciones de su padre ejemplos verdaderamente notables. Así, entre 1224 y 1226 Fernando III apoyó militarmente - mediante una serie de acuerdos que se revistieron de fórmulas feudovasalláticas-a 'Abd Allāh el Baezano, antiguo gobernador almohade de Sevilla y de Córdoba, en su rebelión contra el califa al-'Ādil, teniendo como resultado territorial más evidente la cesión por parte del Baezano de un importante conjunto de fortalezas y villas situadas tanto al norte como al sur de Sierra Morena, entre otros las de Salvatierra, Capilla, Borgalimar, Martos, Andújar y Baeza, esto es, una verdadera cuña castellana clavada en el alto valle del Guadalquivir $^{\prime \prime}$. Entre 1227 y 1229, estableció varios convenios con el califa almoha-

prise de Tolède (1085), «Hesperis», XII (1931), pp. 33-49; Ramón MENÉNDEZ PIDAL, La España del Cid, tomo I, pp. 262-266 y 303-307; Idem. Adefonsus Imperator Toletanus, Magnificus Triumphator, en Historia y Epopeya, Madrid, 1934, pp. 239-262; José MIRANDA CALvo, La Reconquista de Toledo por Alfonso VI, Toledo, 1980; Bernard F. REILLY, El reino de León y Castilla bajo Alfonso VI, 1065-1109, Toledo, 1989.

${ }^{10}$ IBN AL-KaRDabūs, Historia de al-Andalus, p. 102.

"Chronique Latine des Rois de Castille, jusqu'en 1236, ed. Georges Cirot, Bordeaux, 1920. 46-50, p. 107-117 (en lo sucesivo CLRC); HRH, Lib. IX, cap. XII; Las quatro partes enteras de la Crónica de Espanna que mandó componer el Serenissimo rey don Alfonso llamado el Sabio, publicado por Florián de Ocampo, Valladolid, 1604; Crónica de Veinte Reyes, ed. Gonzalo Martínez Díez, César Fernández Alonso, José Manuel Ruiz Asencio et alii, Burgos, 1991, Lib. XIV, caps. VIII-XII, pp. 300-303 (en lo sucesivo CVR); Crónica Geral de Espanha de 1344, edição crítica do texto português pelo Académico Correspondente Luís Filipe Lindley Cintra, 4 vols., Lisboa, 1951-1990, vol. IV, caps. DCCLXXXIV-DCCLXXXVII, pp. 367-375; 'ABD al MUN'In AL-Himyarĩ, Kitāb ar-Rawd al-mi tär Fi Habar al-Aktār, edición y traducción de E. Lévi-Provençal, Leiden, 1938, pp. 73-77; IBN ABİ ZAR', Raw'd al-qirţās, traducido y anotado por Ambrosio Huici Miranda, Valencia, 1964, pp. 524-525; IBN 'IDĀRİ ALMARRĀKUṠī, Al-Bay'ān al-mugrib) fi ijtisär ajbär muluk al-Andalus wa al-Magrib, tomo I, traducción española de Ambrosio Huici Miranda, Tetuán, 1953, pp. 292-295 (en lo sucesivo AlBayān.I); IBN Khaldoun, Histoire des Benou'l-Ahmar, rois de Grenade, traduit par M. 
de al-Ma'mūn para sostenerlo primero contra otros pretendientes al califato y, después, frente a la rebelión de Ibn Hūd, consecuencia de lo cual fue la incorporación de Garcíes, Jódar y otras pequeñas fortificaciones en las fronteras ${ }^{12}$. El apuntalamiento, directo o indirecto, por parte de Fernando III de la rebelión de Muhammad Ibn Mahfūz de Niebla frente a Ibn Hūd en 1234, obligó a éste a aceptar una tregua que implicaba el desamparo de algunas localidades, como Iznatoraf y Santisteban, que pasaron a manos castellanas $^{13}$.

Así pues, la tradición de injerencias en conflictos internos era larga y había demostrado en muchas ocasiones que entrañaba posibilidades de expansión territorial sin requerir el empleo masivo de la fuerza. Alfonso $\mathrm{X}$ no dejaría pasar la oportunidad cuando se presentara, y eso fue lo que ocurrió durante la revuelta mudéjar. Conviene, por tanto, recordar algunas circunstancias previas.

Durante la primera década de su reinado, Alfonso X fue desmantelando progresivamente las bases sobre las que se había asentado la estabilidad de las relaciones entre Castilla y los musulmanes peninsulares en los últimos años de gobierno de su padre. Poco a poco, a fin de consolidar la presencia de pobladores cristianos en aquellas zonas y de afianzar la frontera frente al reino nazarí, el rey castellano fue conculcando las capitulaciones que Fernando III había establecido con las comunidades mudéjares del reino de Murcia, de las campiñas de Córdoba y Sevilla, y del valle del Guadalete. El resultado final de aquella política fue un desplazamiento silencioso de buena parte de la población mudéjar de los núcleos rurales y, en los casos más espectaculares, la expulsión directa de aquellos habitantes, como ocurrió en ciudades tan importantes como Écija y Osuna en 1263. Por otro lado, el monarca fue acabando uno a uno con todos los poderes políticos musulmanes reconocibles, salvo con el reino de Granada: en 1253, sin que sepamos el motivo, aunque tal vez relacionado con la seguridad de los cristianos que estaban iniciando la repoblación de Sevilla, Alfonso X destruyó el reino de

Gaudefroy-Demombynes, «Journal Asiatique», XII (1898), pp. 315-316.

${ }^{12}$ Al-Bayān.I, pp. 296-303 y 313; IBN KHALDOUN, Histoire des Berbères et des Dynasties Musulmanes de L'Afrique Septentrionale, traduite de l'arabe par Le Baron de Slane, París, 1969 vol. II, pp. 232-235; IBN ABĪ ZAR', Rawd al-qirțās, pp. 479-480 y 485-486; CLRC, 53, p. 122; $C V R$, Lib. XIV, cap. XV, p. 304; HRH, Lib. IX, cap. XII.

${ }^{13} C L R C, 67$, pp. 140-141; IBN 'ID̄ĀRĪ AL-MARRĀKUŠĪ, Al-Bayān al-mugrib fi ijtisār ajbār muluk al-Andalus wa al-Magrib, II, traducción española de Ambrosio Huici Miranda, Tetuán, 1954, p. 162 (en lo sucesivo Al-Bayän.II). 
Tejada; en 1261, en el contexto de los preparativos de la Cruzada en África y obligado por la necesidad de controlar previamente los puertos de la bahía de Cádiz, puso fin a la historia del reino musulmán de Jerez; un año después, al objeto de fortalecer sus pretensiones de dominio sobre el Algarbe, disputado con la monarquía portuguesa, cercó y conquistó Niebla ${ }^{14}$.

Al cabo de diez años, sólo el reino de Granada parecía haberse librado de la presión, aunque eso sí, a cambio del pago de parias. Pero aquéllo podía ser un espejismo. Dada la forma en que se habían enrarecido las relaciones entre castellanos y musulmanes peninsulares, los granadinos podían temer que en cualquier momento su propio reino se convirtiera en objetivo militar de Alfonso X. Cuando en mayo de 1262 Muhammad I se entrevistó con el rey de Castilla para proponerle una actuación conjunta en la conquista de Ceuta, empresa en la que el nazarí había fracasado el año anterior ${ }^{15}$, y aquél le exigió a cambio la entrega de los puertos de Algeciras y Tarifa como base de las operaciones navales, en Granada debieron de comprender en toda su extensión el peligro real que se cernía sobre sus cabezas, debieron de entender que el proceso corrosivo y asfixiante al que Alfonso X había sometido a otras comunidades y poderes islámicos de la Península, les afectaba ahora a ellos, así que todos los resortes de alarma saltaron en la corte nazarí, que se negó a cumplir la promesa realizada por Muhammad $^{16}$.

La respuesta dada por los mudéjares y por los granadinos a aquel estado de cosas no sólo fue violenta, sino que además demostró que los musulmanes peninsulares aún podían acudir al norte de Africa para compensar el apremio castellano. Igual que en épocas anteriores, la solución norteafricana se presentaba otra vez a los gobernantes andalusíes como un recurso estratégico, de grandes posibilidades si era manejado con cautela, capaz de contener la presión político-militar castellana en los momentos en

\footnotetext{
${ }^{14} \mathrm{La}$ política de Alfonso $\mathrm{X}$ en relación con las comunidades mudéjares y los reinos musulmanes ha sido estudiada con detalle por Manuel González Jiménez en diversos trabajos. Dos visiones de conjunto ofrecidas por este autor en Alfonso X, 1252-1284, pp. 40-42, 63-65 y 71-78 y Andalucía en tiempos de Alfonso X. Estudio Histórico, en Diplomatario Andaluz de Alfonso X, ed. Manuel González Jiménez, Sevilla, 1991, pp. XLIX-LXIII y LXXI-LXXII (en lo sucesivo $D A A X)$. Con algunas variantes, Joseph F. O'CALlaGHAN, El Rey Sabio, pp. 209222.

${ }^{15}$ Al-Bayān.II, pp. 275-276.

${ }^{16} D A A X$, doc. 286.
} 
que aquélla alcanzaba unos límites intolerables, siempre y cuando existiera, claro está, al otro lado del Estrecho una potencia unificada y con proyección expansiva. Todas estas condiciones se daban, en mayor o menor medida, a comienzos de la década de los años sesenta del siglo XIII. Pero aquella solución implicaba también enormes riesgos y su puesta en práctica podía generar nuevas amenazas para la estabilidad de Granada ${ }^{17}$.

En mayo de 1264 los musulmanes respondieron a la presión castellana con una gran rebelión en la que se vieron envueltos los mudéjares del valle del Guadalete y de Murcia, instigados y apoyados por el rey de Granada y por algunos contingentes meriníes llegados a la Península ${ }^{18}$. La participación en la guerra de estos últimos suponía la apertura de un horizonte estratégico que, si bien no era nuevo en la historia de las relaciones militares castellano-musulmanas, era desconocido en la Península desde los años veinte del siglo XIII. No obstante, la presencia benimerí fue escasa y con unas connotaciones muy precisas que la diferenciarían de las invasiones que se producirían en el último cuarto de esta centuria.

Según la Crónica del rey don Alfonso décimo, Muhammad I "veyendo el gran afincamiento de la guerra en que estaba, envió rogar á Aben Yuzaf que le enviase alguna gente en su ayuda, é enviole mil caballeros, é vino por cabdillo dellos un moro que era tuerto de un ojo, é decian que era de los más poderosos que había allen mar"19. Sin embargo, el propio monarca reconoce en su comunicación al obispo de Cuenca que el rey de Granada había hecho pasar a contingentes de allent mar antes de que se iniciara la revuelta de los mudéjares y la guerra contra los castellanos, coincidiendo en ello con otras fuentes musulmanas y cristianas que dan noticias de aquellos acontecimientos ${ }^{20}$.

\footnotetext{
${ }^{17}$ Sobre ello véase Francisco GARCía FITZ, Estrategias internacionales en el contexto de sociedades de fronteras. La amenaza africana en las relaciones castellano-andalusies, siglos XI al XIII, "II Estudios de Frontera. En memoria de D. Claudio Sánchez Albornoz», Alcalá la Real, 1997 (en prensa).

${ }^{18}$ Sobre ello véase Antonio Ballesteros. Alfonso X el Sabio, Barcelona, 1963, pp. 362417; Manuel GonZÁlez JimÉnEZ, Alfonso X, pp. 77-81; Joseph F. O'Callaghan, El rey' Sabio, pp. 225-234; Juan TORRES FONTES, La reconquista de Murcia en 1266 por Jaime I de Aragón, Murcia, 1965, passim.

${ }^{19}$ Crónica del rey don Alfonso décimo, «Biblioteca de Autores Españoles», LXVI, Madrid, 1953, cap. XIII, p. 10 (en lo sucesivo $C A X$ ).

${ }^{20} D A A X$, doc. 286. Según estas fuentes, la llegada de los efectivos meriníes se produjo entre 1262 y 1264, y su volumen varía según los cronistas entre los tres mil apuntados por lbn Abĩ Zar', Ibn Jaldūn y la Dajīra al-saniyya, y los trescientos señalados por Ibn Id̄ārī, cifra ésta
} 
Aunque una parte de la historiografía meriní posterior no dudó en presentar la participación de efectivos norteafricanos en la guerra de 1264 como la primera de sus expediciones en la Península ${ }^{21}$, el alcance real de esta intervención fue limitado. Sabemos que los benimerines que acudieron a la llamada del rey nazarí fueron recibidos en Tarifa y que posteriormente se establecieron en Málaga, donde permanecieron hasta que se inició la revuelta en Jerez. Fue allí, en el asalto y la defensa de Jerez y tal vez de los enclaves comarcanos, donde concentraron sus esfuerzos, sin que tengamos noticias de su participación en otras operaciones ${ }^{22}$.

Lo restringido de su intervención en la guerra contra Castilla no era sólo consecuencia de la debilidad del número de efectivos que pasaron desde el norte de Africa o de su concentración exclusiva en Jerez y sus alrededores, sino también de la propia índole de su participación, ya que resulta cuanto menos dudoso suponer que la colaboración meriní en el conflicto iniciado en 1264 fuera el fruto de un acuerdo entre Muhammad I y el emir Abū Yūsuf en orden a una implicación directa de éste último en las cuestiones peninsulares.

El caudillo benimerí que dirigía a los contingentes norteafricanos era Abū 'Abd Allāh Muhammad b. Idrīs, uno de los jefes de una facción disidente del tronco dinástico meriní que en 1261-1262 se había rebelado contra el emir en las montañas de Gomara y a quien Abū Yūsuf obligó a cruzar el Estrecho con el estandarte de la guerra santa ${ }^{23}$, con lo que, como ha señalado Miguel Manzano, el emir alejaba a los rebeldes al tiempo que conseguía "transformar su oposición frente al estado magrebí en un servicio

última más verosímil que la primera, véase IBN $\mathrm{ABĪ} \mathrm{ZAR}^{\mathrm{C}}$ Rawd al-qirțās, p. 575; IBN KHALDOUN, Histoire des Berbères, vol. IV, pp. 48 y 75; al-Dajíra al-saniyya fi ta'rij al-dawla al-mariniyya, trad. parcial de José Manuel Continente en Dos poemas de Málik ibn alMurahhal, poeta malagueño al servicio de los benimerines, "Awrāq", 2 (1979), p. 48 (en adelante: al-Dajíra); IBN CIDĀRİ AL-MARRĀKUŠi, al-Bayān. II, p. 285. El Llibre dels fets de Jaime I también indica que cuando el rey de Granada rompió sus relaciones con Alfonso X hacía ya algún tiempo que había llamado en su ayuda a los musulmanes de ultramar (Llibre dels fets, trad., pról. y not. de Enrique Palau, Barcelona, 1958, vol. II, cap. CXXVIII, p. 129).

${ }^{21} L a$ Dajira la presenta como la primera de las intervenciones de los benimerines en la Península, mientras que Ibn Marzūq, aunque equivocando el año, la citó como la primera de las cuatro veces que Abū Yūsuf cruzaría el Estrecho a lo largo de su vida "en pie de Guerra Santa", véase al-Dajïra, p. 48 e IBN MARZūQ, El Musnad: Hechos memorables de Abü lHasan, sultán de los benimerines, est., trad., anotación e indices por María Jesús Viguera, Madrid, 1977, p. 101.

"2IBN C'IDĀRì AL-MARRĀKUŠī, al-Bay'ān. II, p. 288.

${ }^{23}$ IBN KHALDOUN, Histoire des Berbères, IV, p. 48. 
específico que redundaba en favor del sultanato de Granada, justamente cuando las circunstancias tampoco permitían una intervención militar en la Península"24.

No obstante, por circunstancial que fuese la presencia de expedicionarios benimerines al servicio del rey de Granada, se trataba de un nuevo factor que los castellanos debían de empezar a tener en cuenta al afrontar en el futuro sus relaciones con el reino nazarí, y no sólo porque su injerencia en la política peninsular pudiera constituir una amenaza potencial para la estrategia de expansión castellana o para la consolidación de sus más recientes conquistas, sino también porque, en el ámbito granadino, la intervención de elementos foráneos podía acarrear cierto grado de inestabilidad y tensión en la forma de articulación y reparto del poder en el interior del estado, que abriría algunos intersticios aprovechables para la actividad diplomática de Castilla mediante la vieja estrategia del desequilibro y desintegración del adversario.

Pues bien, entre los nuevos horizontes estratégicos que se le planteaban a Alfonso X como consecuencia de la reaparición del elemento africano, el primero en materializarse sería precisamente el último de los comentados, esto es, la ruptura de las solidaridades familiares en el seno de las élites políticas y sociales del reino de Granada a raíz de la llegada y asentamiento de los guerreros benimerines, con el inevitable realineamiento de fuerzas en el interior del Estado y las fricciones inherentes a dicho proceso.

El ascenso al poder de Muhammad Ibn al-Ahmar en 1232, su posterior consolidación y la expansión de su dominio desde Arjona a otras localidades andaluzas estuvo estrechamente relacionado con el apoyo que le prestaron los jefes de otras familias que, al igual que los Banū Nasr, basaban su prestigio en la condición de hombres de guerra acostumbrados a combatir a los cristianos, entre las cuales habría que destacar a los Banū Sanādid de Jaén, los Banū Mawl de Córdoba y, sobre todo, los Banū Ašqīlūla, cuya cabeza visible en aquellos primeros momentos, Abū-l-Hasan 'Alī, además de ser el principal colaborador de Ibn al-Ahmar en la revuelta contra Ibn Hūd, y su mano derecha en asuntos militares ${ }^{25}$, estaba unido al nazarí por

\footnotetext{
${ }^{24}$ Miguel Ángel Manzano Rodríguez, La intervención de los benimerines en la Península Ibérica, Madrid, 1992, p. 5.

${ }^{25}$ Por ejemplo, había sido Abū-l-Hasan 'Alī Ibn Ašqīlūla quien en 1233 dirigió la conspiración que permitió al nazarí tomar posesión de Sevilla, IBN KHALDOUN, Histoire des Berbères, II, p. 320 y vol. IV, p. 78 e Histoire des Benou'l-Ahmar, p. 322.
} 
vínculos familiares - estaba casado con una hermana del monarca granadino- y contaba con la promesa de compartir el reino que acababan de fundar ${ }^{26}$.

Además, los Banū Nasr y los Banū Ašqūlūla estaban unidos por vínculos cognáticos de parentesco, pues tanto Abū-l-Hasan 'Alī como sus dos hijos, Abū Ishāq Ibrāhīm y Abū Muhammad 'Abd Allāh, estaban casados respectivamente con una hermana y dos hijas de Muhammad $\mathrm{I}^{27}$. Dado que en la sociedad granadina las relaciones cognáticas llegaron a tener tanta fuerza como las agnáticas y que las mujeres podían transmitir la nobleza de su linaje, se comprende que los Banū Ašqīlūla llegasen a tener el mismo título honorífico - arraeces - que los agnados o parientes directos del rey de Granada ${ }^{28}$.

En términos políticos, las estrechas relaciones militares y familiares de los dos clanes se tradujo, una vez que el reino se asentó, en un importante reparto del poder, en virtud del cual los Ašqīlūla se reservarían el control del ejército nazarí y el dominio sobre Comares, Guadix y Málaga, con los territorios de sus respectivas demarcaciones ${ }^{29}$.

A pesar de los avatares por los que hubo de pasar el equilibrio alcanzado entre las dos familias, provocados a raíz de que Muhammad I designase como herederos del sultanato a sus hijos y relegase los derechos sucesorios de los cognados en $1257^{30}$, y a pesar de que las fuentes apunten, aunque de una manera un tanto confusa, el descontento de los Banū Ašqīlūla hacia los Nasr como consecuencia de algunas actitudes de Muhammad I o del príncipe heredero ${ }^{31}$, lo cierto es que los primeros se mantuvieron con fidelidad al servicio del rey de Granada hasta 1264, como demuestra el hecho de que

\footnotetext{
26" Ils -Muhammad I y Abū-l-Hasan 'Alī- avaient convenu tous deux qu'ils se partageraient le royaume qu'ils auraient réussi à fonder", IBN AL-JATīB, Kitäb A'māl al-A'läm, trad. parcial de I.S. Allouche en La révolte des Banū Aškilüla contre le sultan naşríde Muhaminad II, d'après le "Kitāb A'māl al-A'lām» d'Ibn al-Hatīb, "Hespéris», XXV (1938), p. 4 (en lo sucesivo: Kitāb $A$ 'māl).

${ }^{27}$ Ibidem.

${ }^{28}$ María Jesús RUBIERA MATA, El vínculo cognático en al-Andalus, «Actas del I Congreso de Historia de Andalucía: Andalucía Medieval», I, Córdoba, 1982, pp. 121-124.

${ }^{29}$ IBN Khaldoun, Histoire des Berbères, IV, pp. 78 y 89; IBN AL-JATīB: Kitāb A'māl, pp. 4-5. Véase también Rachel ARIÉ, op. cit., pp. 65-66 y María Jesús RUBIERA MATA, Los Banū Escallola, la dinastía granadina que no fue, "Andalucía Islámica», II-III (1981-1982), pp. 8889

${ }^{30}$ Rachel ARIÉ, op. cit., p. 66.

${ }^{31}$ IBn Khaldoun, Histoire des Berbères, IV, p. 89; IBN AL-JATīB, Kitāb A'māl, p. 5.
} 
tras la rebelión de los mudéjares murcianos fuera un miembro de este clan, Abū Muhammad 'Abd Allāh, el encargado por el monarca del gobierno de los nuevos súbditos nazaríes ${ }^{32}$.

Fue durante el desarrollo de la guerra contra Castilla cuando los Banū Ašqīlūla se rebelaron por primera vez contra el monarca nazarí, y parece que la causa hay que buscarla en la ruptura de los equilibrios internos granadinos como consecuencia de la llegada de las tropas meriníes. La participación en el conflicto de los contingentes norteafricanos requería una modificación de la estructura militar granadina en orden al establecimiento de nuevas líneas de mando y de distintos repartos de los recursos financieros destinados al mantenimiento del ejército, lo que vendría a incidir directamente sobre una parcela del poder, el ejército, que hasta entonces había estado exclusivamente en manos de los Ašqīlūla. De hecho, la utilización de tropas meriníes implicaba un realineamiento de fuerzas en el interior del estado granadino que perjudicaba gravemente a la esfera de influencia de éstos últimos y con ello a uno de los equilibrios sobre los que se había asentado el estado nazarí desde sus orígenes.

Según la Crónica del rey don Alfonso décimo, Muhammad I honró a los guerreros norteafricanos "en todas las cosas, é por los tener más pagados dábales muy grandes soldadas", sin duda en detrimento del control de los resortes militares del reino de Granada que hasta entonces habían poseido los Ašqīlūla. Los arraeces de Málaga y Guadix procuraron reestablecer el statu quo e intentaron convencer a Ibn al-Ahmar de que desposeer a los suyos en beneficio de extraños era una torpeza que debía de ser reparada, pero sus razonamientos no fueron atendidos ${ }^{33}$.

Como decíamos, la actitud del monarca nazarí atentaba contra el reparto de esferas de poder entre los clanes fundacionales sobre el que se

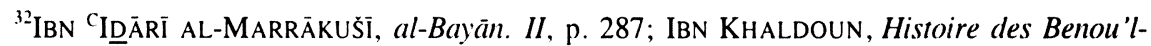
Ahmar, p. 320.

${ }^{33}$ Cap. XIII, p. 10. Aunque se refiere a hechos posteriores, ocurridos con motivo de la llegada de otros contingentes meriníes a la Península en 1272, también dirigidos por los Banū Idrīs, Ibn Jaldūn señala que estos expedicionarios exigieron del rey de Granada una serie de concesiones, entre ellas la posesión de todo lo que pudieran conquistar en tierras cristianas, la cesión del mando sobre todos los grupos beréberes que habían cruzado el Estrecho y la entrega de una parte de los impuestos destinados a pagar las soldadas. Es probable que en 1264 se produjera una situación similar y que a ella se refiera la Crónica del rey don Alfonso décimo, lo que explicaría plenamente el descontento de los Ašqīlūla. El testimonio de Ibn Jaldūn en Histoire des Berbères, vol. IV, p. 59. Véase también María Jesús RuBiera Mata, Los Banū Escallola, la dinastía granadina que no fue, pp. 89-90.
} 
había construido el reino y en el que se había basado su estabilidad. La gravedad de aquella ruptura fue muy pronto percibida por los Ašqīlūla, que en plena guerra contra los castellanos se rebelaron en las demarcaciones que dominaban y acudieron a solicitar la ayuda de Alfonso X.

Como es fácilmente imaginable, el rey de Castilla no dejaría pasar la ocasión de aprovechar los efectivos y bases territoriales que le ofrecían los rebeldes contra el nazarí, y de debilitar a Muhammad I en su propio reino apoyando a sus enemigos, así que atendió la petición de socorro de los Banū Ašqīlūla y les envió un importante contingente de tropas. Si hemos de creer el testimonio de la Crónica del rey don Alfonso décimo, el efecto de la alianza entre los sediciosos y el monarca castellano desequilibró la posición militar y política de Ibn al-Ahmar de manera fulminante, hasta el punto de que éste se vio obligado casi inmediatamente a negociar una tregua - firmada en Alcalá la Real en 1267- del todo desfavorable para los intereses granadinos, en la que se preveía la reanudación del pago de parias y la colaboración de Muhammad I en la represión de la revuelta de los mudéjares murcianos. Significativamente, la única contrapartida importante exigida por éste último al castellano fue el desamparo de los Ašqīlūla. Pero la colaboración con ellos había tenido para Castilla un resultado demasiado rentable como para desechar las posibilidades de su explotación en el futuro, de modo que Muhammad I únicamente consiguió de Alfonso el compromiso de abandonar a los arraeces a su suerte a cambio del establecimiento de una tregua de un año entre Ibn al-Ahmar y los rebeldes, lo que en la práctica venía a significar una prolongación del apoyo de Castilla a los Banū Ašqīlūla ${ }^{34}$.

\footnotetext{
${ }^{34}$ Cap. XV, p. 11. Esta fuente no indica si Muhammad I realizó algún tipo de contraprestación territorial a Alfonso $\mathrm{X}$ a cambio de que éste dejara de apoyar a los arraeces o de que se aliara con el nazarí si al cabo de un año los Ašqīlūla no habían vuelto a la obediencia de la corte granadina. Sin embargo uno de los protagonistas de estos acuerdos - Muhammad IIsostendría mucho tiempo después - en 1301 - que el monarca castellano habría recibido las villas de Alcalá de los Gazules, Medinasidonia, Vejer de la Frontera y Castel (Castellar?) "porque vos ayudasse - a los nazaríes - contra los vuestros enemigos fijos de Escayuela" y que posteriormente Alfonso X se habría negado a retornarlas al domino granadino. La existencia de esta cesión resulta problemática por dos motivos: en primer lugar, el testimonio del segundo monarca nazarí se encuentra en un acuerdo de colaboración firmado por éste y Alfonso de la Cerda, en virtud del cual este último se comprometía a devolver a Granada los castillos que Alfonso X "tenia forçados" por el presunto incumplimiento de su palabra, de manera que la opinión de Muhammad II resulta de todo punto interesada; en segundo lugar, porque la Crónica de Alfonso $X$ sitúa las anexiones de Vejer y Medinasidonia en relación con la campaña de conquista de Jerez de 1266, un año antes de las vistas de Alcalá la Real. No obstante, si realmente llegó a producirse la entrega de estas localidades, tendría que haber sido con
} 
Para Muhammad I, el hecho de que los castellanos protegiesen y sostuviesen la disidencia interna constituía el mayor de los peligros con los que hasta entonces, en sus casi veinticinco años de historia, había tenido que enfrentarse, puesto que, al margen de las potenciales amenazas que podrían cernirse en el futuro sobre su carrera política y la de su dinastía, en la práctica la rebelión de los Ašqīlūla venía a significar una importante fragmentación del reino ${ }^{35}$.

Por su parte, el rey de Castilla no estaba dispuesto a renunciar a una herramienta diplomática cuyas consecuencias políticas y militares paralizaban a Muhammad I. Ambos contrincantes eran plenamente conscientes de la situación. Cuando se cumplió la tregua de un año establecida entre Ibn alAhmar y los Banū Ašqīlūla, el rey de Granada se entrevistó con Alfonso X para exigirle mucho afincadamente que cumpliera la parte que le correspondía en el acuerdo, es decir, el desamparamiento de los sediciosos.

La respuesta dada por Alfonso X, tal como fue recogida en la Crónica de su reinado, es de todo punto esclarecedora de los efectos que se esperaban de la aplicación de una estrategia de injerencia y de avivamiento de los conflictos intestinos de un adversario. Según aquel testimonio, el rey de Castilla entendía que la ayuda que prestaba a los arraeces era el vehículo adecuado para tener permanentemente presionado al monarca nazarí, de forma tal que el apremio podría traducirse bien en la conquista de los territorios nazaríes, bien en la extracción de sus rentas por la vía de la exigencia

anterioridad a 1268, fecha en que Alfonso X concedía diversas franquicias a los habitantes de Medinasidonia y entregaba alquerías a ciertas personas en el término de Alcalá. De ser cierta esta noticia proporcionada por Muhammad II, la envergadura de la cesión nos daría una idea de la urgencia de los granadinos por acabar con la rebelión, puesto que aquella franja fronteriza tenía una importancia estratégica fundamental para consolidar la presencia castellana en el valle del Guadalete. De hecho, el triángulo formado por Alcalá, Vejer y Medinasidonia constituiría la primera línea de frontera castellana hasta el siglo XV. Sorprende la entidad de lo presuntamente concedido, no la cesión en sí, puesto que sabemos que unos años más tarde -1272 ó 1273- Muhammad II "queria dar alguna parte de la tierra que avia - a Alfonso Xé que desamparase a los arrayaces é le diese ayuda para los conquerir, porque él -el nazarípudiese cobrar las tierras que ellos tenian". El texto del acuerdo en Andrés GimÉNEZ SoLER, La Corona de Aragón y Granada, Barcelona, 1908, pp. 80-81; la referencia cronística a la anexión de Vejer y Medina en $C A X$, cap. XIV, p. 10; los primeros documentos sobre repoblación de Alcalá, Vejer y Medina en $D A A X$, docs. 343, 346 y 348; la disponibilidad del granadino a entregar tierras en 1272 en "CAX», cap. XLV, p. 34. Sobre el acuerdo firmado por Alfonso X y Muhammad I en Alcalá la Real véase también Pedro CANo Ávila, Alcalá la Real en los autores musulmanes, Jaén, 1990, pp. 60-61.

${ }^{35}$ Según Ibn al-Jatīb, tras las desavenencias con Muhammad I y con su heredero, los rebeldes se mantuvieron independientes en Guadix y Málaga, aunque respetando formalmente el reconocimiento de su soberanía, Kitāb $A$ 'māl, p. 5. 
de parias. En cualquiera de los dos supuestos, el mantenimiento de la protección castellana a los rebeldes venía a suponer para Granada una verdadera servidumbre respecto a los deseos del gobernante cristiano. El texto revela claramente el tipo de beneficio que un dirigente político podía esperar de una estrategia diplomática y de unas alianzas como las que mantenía el monarca castellano con los rebeldes granadinos, así que conviene reproducirlo:

\begin{abstract}
E el Rey -Alfonso X- veyendo que por el ayuda que él tenía de los arrayaces podria siempre tener apremiado al rey de Granada para cobrar dél la mayor partida de su reino, ó que le sirviese siempre con las rentas del reino, non quiso desamparar los arrayaces, ántes le dijo - a Muhammad Ique los ampararia é defenderia porque oviessen el señorío sobre sí, é que non obedesciesen al rey de Granada ni á otro ninguno. E por esta razón el rey de Granada partióse del Rey muy despagado, lo uno porque le non guardara la postura que con él avia, é lo al porque veia que le queria tener siempre en servidumbre ${ }^{36}$.
\end{abstract}

Partiendo de estas presunciones, no debe extrañar que el rey de Castilla se negara a cumplir el compromiso suscrito el año anterior, faltando paladinamente a los acuerdos contraídos. Jaime I, que fue consultado al respecto por Alfonso X, también compartía la opinión de que la persistencia de la división interna en el reino de Granada otorgaba suficientes ventajas estratégicas al rey de Castilla como para obviar el cumplimiento de los compromisos previos, cualesquiera que fuesen. Así, preguntado por el monarca castellano sobre el mantenimiento o no de los acuerdos a los que había llegado con Muhammad I, su respuesta fue concluyente:

\footnotetext{
...le dijimos que, si se había comprometido con el rey de Granada, a éste le prestase ayuda siempre que no hubiese roto el convenio; pero, que en caso contrario, dejase a dicho rey y la ofreciese antes bien a los demás arraeces, con los cuales se podría convenir, y que no por ésto valdría menos su fe. Por último, le dijimos que nos placía mucho el que diera así ocasión de dividir a los moros en dos bandos, pues en mucho valía ello y no que formasen una sola partida ${ }^{37}$.
}

\footnotetext{
${ }^{36} C A X$, cap. XVI, pp. 11-12.

${ }^{37}$ Llibre dels fets, II, cap. CLIII, pp. 216-217.
} 
La apuesta estratégica de Alfonso $\mathrm{X}$ era decidida, pero entrañaba riesgos, tanto por la situación interna castellana como, sobre todo, por la tonalidad que estaba adquiriendo entonces el panorama político internacional en torno al Estrecho de Gibraltar.

En Castilla, el descontento larvado de la alta nobleza se hizo patente en 1272 y se convirtió en franca rebeldía. Dado el turbio cariz de las relaciones castellano-nazaríes, la corte granadina se convirtió en asilo de la nobleza levantisca, de forma que Muhammad I no sólo se colocaba en mejor posición para negociar con Alfonso X sobre el futuro de los arraeces, sino que también podía utilizar a los efectivos nobiliarios contra los Banū Ašqīlūla ${ }^{38}$.

A lo largo de las negociaciones que se desarrollaron durante 1272 y 1273 entre los nobles castellanos rebeldes, el rey de Granada y Alfonso X, desgranadas con bastante detalle en la Crónica del rey don Alfonso décimo a lo largo de treinta capítulos, se puso de manifiesto que el interés central de los dos monarcas enfrentados giró en torno a la cuestión de los arraeces, no desapareciendo en ningún momento de las negociaciones la posibilidad de la amenaza meriní.

Las líneas estratégicas de los dos contendientes se fueron dibujando con toda precisión en el transcurso del conflicto. Muhammad I y, a su muerte, Muhammad II, establecieron como prioridad acabar con los Ašqīlūla, valiéndose para ello de la fuerza de los nobles castellanos, quienes, en virtud de los acuerdos establecidos con el monarca nazarí, atacaron Guadix y otros territorios rebeldes al granadino ${ }^{39}$, y manteniendo a toda costa, como condición irrenunciable a lo largo de las negociaciones, el abandono de los arraeces por parte del rey de Castilla. Así, por ejemplo, en uno de los primeros acercamientos entre Castilla y Granada, realizado por mediación de la reina doña Violante y el infante don Manuel, en el que Alfonso X proponía una tregua de un mes en la que éntrasen los arraeces, Muhammad II se negó, alegando que, aunque quería servir al rey de Castilla y firmar una tregua con los cristianos, "con los arrayaces nunca avria tregua; é cuando todo el mundo le fallesciese, que ante daria la tierra á Aben-Yusaf,

\footnotetext{
${ }^{38}$ Sobre la rebelión nobiliaria véase $C A X$, caps. XVI y XIX-LVIII.

${ }^{39}$ Ibidem, caps. XLIII y XLVI. Véase también Crónica del rey don Alfonso el Onceno, «Biblioteca de Autores Españoles», LXVI, Madrid, 1953, cap. LII, p. 205.
} 
que dar tregua á los arrayaces... pero que si el rey de Castilla non quisiese ayudar a los arrayaces, que el rey de Granada le serviria"40.

Los nazaríes estuvieron dispuestos a ceder en todas las exigencias de Alfonso X, incluyendo la entrega de algunos territorios, la reanudación del pago de parias, la ruptura de los pleitos-homenajes establecidos con los ricos hombres castellanos, y la restauración del vínculo de vasallaje ${ }^{41}$, pero se negaron de manera rotunda a aceptar la división del reino que implicaba el respeto a los Ašqīlūla.

Además, para reforzar la contundencia de sus requerimientos, el rey de Granada esgrimió en todo momento la baza de la llamada a los benimerines, quienes en 1272 volvieron a actuar en el valle del Guadalete, establecieron contactos con los nobles castellanos y se convirtieron en la amenaza última a la que podían recurrir los granadinos para conseguir sus pretensiones ${ }^{42}$.

Entre tanto, la política de Alfonso X se esforzó en todo momento por sostener a los Banū Ašqīlūla, convirtiendo su integridad en condición sine qua non de cualquier acuerdo con los nazaries y con la aristocracia rebelde. Reiteradamente, con una persistencia asombrosa e incluso con un vigor que contrasta con algunas actitudes regias bastante tibias respecto a otras cuestiones relacionadas con el alzamiento de los nobles, el rey de Castilla mantuvo a todo trance la defensa de los arraeces, a los que consideraba "omes con quien el podria apremiar al rey de Granada" y con cuya ayuda "en poco tiempo cobrára dél" — de Muhammad II — "á Granada é todo lo que él avíe" ${ }^{\prime 4}$.

Pero, al mismo tiempo, Alfonso X comenzaba a diseñar una estrategia tendente a la neutralización del peligro norteafricano, mediante la exigencia al monarca nazarí de la entrega de los puertos del Estrecho. Las intenciones alfonsíes respecto a los arraeces y al control del paso de los benimerines aparecen claramente combinadas a lo largo de la negociación, pero especialmente en algunas de las propuestas realizadas por el rey de

\footnotetext{
${ }^{40} C A X$, cap. XLIV. No fue ésta la única vez a lo largo de las negociaciones que los nazaríes exigieron el desamparo de los arraeces para avenirse a un acuerdo con Castilla, véase, por ejemplo, Ibidem, caps. XLVIII, L y LI.

${ }^{41}$ Ibidem, caps. XLV, XLVIII, LI y LVIII.

${ }^{42}$ Véase Ibidem, caps. XIX, XXII, LII, LVII y LVIII; IBN KHALDOUN, Histoire des Berbères, IV, pp. 58-59.

${ }^{43} C A X$, caps. XLIV, XLV, LII, LIV, LV, LVII y LVIII.
} 
Castilla. Así, en un momento de las mismas, Alfonso X·llegó a plantear a Muhammad II tres posibles soluciones alternativas al conflicto que demuestran claramente las prioridades estratégicas castellanas: la primera de ellas consistía en la cesión por parte de Granada de los puertos de Algeciras, Tarifa y Málaga, y el mantenimiento de los arraeces en Guadix, a cambio de una condonación de las parias por diez años; la segunda preveía que Muhammad II se hiciera con el dominio sobre Málaga y Comares, los Banū Ašqīlūla con Baza y Guadix, y Castilla con Algeciras y Tarifa, comprometiéndose además a librar a los granadinos de las parias de seis años en compensación; la tercera alternativa suponía la cesión a Castilla de los puertos de Algeciras y Tarifa y la entrega al rey de Granada de todos los territorios dominados por los arraeces (Málaga, Guadix y Comares), mientras que éstos recibirían en compensación tierras del rey de Granada y de Alfonso $\mathrm{X}^{44}$.

De todas formas, tanto en la corte castellana como en la nazarí parecía evidente que la discusión en torno a los puertos del Estrecho no constituía un problema insalvable, pues, desde la perspectiva granadina, las pretensiones expansionistas de Alfonso X podían ser satisfechas, llegado el caso, con la cesión de otros castillos en la frontera ${ }^{45}$, mientras que desde la alfonsina la demanda de Algeciras y Tarifa no volvió a resurgir en el curso de las negociaciones.

Era evidente, por tanto, que la única cuestión que no tenía salida diplomática era la de los arraeces, pues no en balde se trataba de un problema vital para la supervivencia del reino de Granada. Por supuesto, siempre quedaba el recurso a la guerra, pero ninguno de los dos contendientes estaba en aquellos momentos en condiciones de iniciar las operaciones bélicas con garantías: Alfonso X, porque se sentía apremiado por la consumación del fecho del Imperio, y porque, a pesar de contar con el apoyo aragonés, sus recursos militares, con buena parte de la alta nobleza refugiada en Granada y los problemas internos que ello conllevaba, eran muy limitados ${ }^{46}$;

\footnotetext{
${ }^{44}$ Ibidem, cap. XLV.

${ }^{45}$ Según la Crónica del rey don Alfonso décimo Muhammad II "cuidó que el rey don Alfonso non le demandaría tan gran fecho commo eran los puertos de Algecira é de Tarifa, é cuando algo quisiese, que dándole un castillo ó dos de los que eran fronteros de cristianos, que se ternia por pagado" (cap. XLVIII, p. 36).

${ }^{46}$ Sobre la precariedad de las huestes alfonsinas véase Ibidem, caps. LII, LIII y LVI. Sobre el apoyo de Jaime I, cap. LVII.
} 
Muhammad II, porque únicamente podía hacer frente a los arraeces contando con la participación de los nobles castellanos rebeldes, y éstos no podían emplearse a fondo contra los Banū Ašqīlūla porque peligraban sus haciendas en Castilla ${ }^{47}$.

Parecía, por tanto, que se había entrado en una dinámica sin solución posible. Pero un viejo adagio granadino, expresado por el último de los reyes de la dinastía zīrí, decía que la guerra era puro ardid, de modo que si no puedes ganar, siempre cabe el engaño. Después de todo, por lo que llevamos visto, sabemos que las relaciones políticas también eran la guerra, por otros medios claro, pero la misma guerra. Así que la salida propuesta por los nobles rebeldes, y aceptada por los negociadores castellanos, a la sazón la reina doña Violante y el infante don Fernando, se basó precisamente en eso, en el engaño.

Una vez que los ricos hombres consiguieron que Alfonso $\mathrm{X}$ se plegara a la mayor parte de sus exigencias, sugirieron a los representantes del rey de Castilla que atrajesen al monarca nazarí con la promesa de que se le perdonarían todas las querellas que Alfonso pudiera tener con Muhammad II o con su padre, y de que el monarca castellano estaba dispuesto a acatar los acuerdos de 1268, pero sin mencionar expresamente el problema de los arraeces. Así planteado, Ibn al-Ahmar acudiría a firmar los pactos en la creencia de que los Banū Ašqīlūla serían desamparados, y sólo entonces, cuando hubiese accedido a la parte que le correspondía en el acuerdo, esto es, la ruptura de los pleitos que tenía con los nobles castellanos, la entrada en vasallaje y el pago de trescientos mil maravedís al año en concepto de parias, le exigieran una tregua con los arraeces por dos años ${ }^{48}$.

Muhammad II, presionado por los nobles rebeldes castellanos que hasta entonces habían sido la principal baza en las negociaciones con Castilla, por la reina doña Violante y por el infante don Fernando, se vió obligado a acceder de mala gana. La reunión de Sevilla había sido una encerrona

\footnotetext{
${ }^{47}$ Cuando los nobles castellanos atacaron Guadix, el arráez se dirigió a Alfonso X en busca de socorro, el cual envió comunicar a los agresores que "cuanto dapno ficiesen al arrayaz su vasallo, que de los sus bienes gelo entregaría", concluyendo el cronista que "esto - la advertencia de Alfonso X- excusó gran parte del mal que pudieran facer al arrayaz" (Ibidem, cap. XLIII). En adelante los rebeldes castellanos se guardaron de presionar en exceso a los arraeces como se pone de manifiesto en el cap. XLIV, cuando los ricos hombres reconocen que, en servicio de Alfonso X, "le non ficieron - al arráez de Guadix - tanto daño e mal commo pudieran".

${ }^{48}$ Ibidem, caps. LIV y LVIII.
} 
para el monarca nazarí, de quien la Crónica del rey don Alfonso décimo dice que "pesóle mucho con este ruego - la solicitud de la tregua de dos años para sus parientes-, "ca entendió que gelos querian amparar é que avian levado dél el aver que él dió porque los desamparasen, é de su voluntad non lo quisiera facer, pero por el grand afincamiento de la Reina é del Infante ovo á otorgar esta tregua a los arrayaces por un año"49.

Así las cosas, a fines de 1273 Muhammad II se encontraba con el reino fragmentado, sin el apoyo de los nobles castellanos, que se habían reintegrado a la obediencia de Alfonso X, y sufriendo un grave punzamiento en sus rentas, lo que venía a significar que se hallaba otra vez en un estado de servidumbre e indefensión frente a Castilla. Una vez más, el autor de la crónica del reinado de Alfonso X recogió con gran expresividad la profunda frustración y la amarga desolación que sintió el monarca nazarí después del engaño de Sevilla, en unos términos tan elocuentes que conviene reproducirlos:

Gran pesar avia el rey de Granada por la tregua que dió á los arrayaces estando él en Sevilla, que avia dado al Rey - de Castilla - grand algo, é avia roto la carta del pleito que los ricos-omes avian con él; todo esto avia fecho cuidando que los arrayaces fincarían en manera que los pudiese conquerir é tomarles la tierra que tenien. E entendió, que pues fincaban en tregua con él por aquel año, que despues de aquel tiempo el rey de Castilla querria tornar á los defender, é así fincaba él deste pleito con daño, é los arrayaces fincaban señores en la tierra ${ }^{50}$.

Parecía, pues, que la estrategia de disolución surtía algunos de los efectos para los que había sido diseñada. Pero, en realidad, Alfonso X había llevado demasiado lejos su presión y había colocado a Muhammad II en la disyuntiva de someterse - presumiblemente en espera de nuevas exigenciaso de buscar ayuda militar al otro lado del Estrecho, lo que en la práctica vendría a significar, una vez que se produjese la irrupción meriní en 1275, la ruina de aquella estrategia.

No obstante, siendo ésta una razón fundamental del descalabro de la política alfonsí frente a Granada, hubo otra relacionada con los Banū Ašqīlūla igualmente determinante de aquel colapso. Cuando el monarca castellano

\footnotetext{
${ }^{49}$ Cap. LVIII, p. 47.

${ }^{50}$ Ibidem, cap. LXI, p. 48.
} 
inició su periplo fuera de la Península para resolver el fecho del Imperio, estaba absolutamente convencido de que las amenazas granadinas sobre una posible intervención de los norteafricanos eran mera chufa, por utilizar la expresión alfonsina ${ }^{51}$. Sin embargo, no parece que todos los afectados participasen de la misma confianza. Es posible que sus aliados musulmanes, los Ašqīlūla, no compartiesen esta certeza y consideraran, por el contrario, que no debía despreciarse tan apresuradamente la capacidad potencial de los benimerines. Además, también pudiera ocurrir que los rebeldes granadinos tuvieran recelos acerca del resultado último de las negociaciones entre Castilla y Granada, y pensaran que los adversarios podían por fin encontrar una solución al conflicto sacrificándolos a ellos. Ya fuera por una razón u otra, o quizás por las dos al mismo tiempo, lo cierto es que en 1273 el arráez de Málaga envió mensajeros al Emir meriní para ofrecerle su sumisión -confirmada al año siguiente- de manera que Abū Muhammad Ibn Ašqīlūla aparecía ya como un subordinado de Abū Yūsuf y su gobierno sobre la ciudad se establecía en términos de delegación del poder del Emir $^{52}$.

Diplomáticamente hablando, habrá que reconocer que se trataba de un movimiento inteligente, puesto que sin renunciar formalmente a la protección castellana -recuérdese que los contactos con el Emir benimerí se realizaron al mismo tiempo que Alfonso X imponía a Muhammad II una tregua que los amparaba-, los Ibn Ašqīlūla habían conseguido reforzar su posición tanto frente a los nazaríes como frente a los posibles desamparos por parte de Castilla.

Ciertamente la situación nazarí siguió siendo similar, puesto que los meriníes continuaron apoyando a los arraeces, con lo que la estrategia política de disolución quedaba ahora en manos norteafricanas. De hecho, aunque Muhammad II colaboró - sin demasiado entusiasmo- en las campañas meriníes del año 1275 , sus reticencias no dejaron de crecer hasta

\footnotetext{
51 "Yo non lo puedo creer que pueda ser, nin tanta ayuda commo ellos dicen que le farán", le confesaba a su hijo, concluyendo que "tengo que non puede pasar así como chufan esos que están en Granada" Ibidem, cap. LII, p. 39. Ideas similares en cap. LVIII, p. 47.

${ }^{52}$ IBN Khaldoun, Histoire des Berbères, IV, p. 89. Las crónicas cristianas recogen otra versión de los hechos, aunque señalando también el cambio de actitud de los arraeces. Según la Crónica del rey don Alfonso décimo, después del pacto de Sevilla Muhammad II le habría propuesto a sus familiares rebeldes que se le sometiesen, a cambio de dejarles las tierras que dominaban, a lo cual habrían accedido éstos, "sabiendo commo el rey don Alfonso se iba al Imperio, é rescelando que si el rey de Granada les ficiese guerra, que non serien acorridos" (cap. LXI, p. 48).
} 
que dos años más tarde diera un giro diplomático y se acercara a Castilla en contra de la presencia benimerí y de los Ašqīlūla ${ }^{53}$. Pero desde la perspectiva castellana parece claro que Alfonso $\mathrm{X}$ había perdido definitivamente la herramienta política que tanto había cuidado y con la que había intentado desestabilizar al reino de Granada.

Es posible que la explotación de las disidencias internas granadinas de las décadas de los años sesenta y setenta del siglo XIII no fuera demasiado fructífera desde el punto de vista territorial, a no ser, claro está, que Muhammad II tuviera razón cuando afirmaba que su padre había entregado a Alfonso X las villas y castillos de Medinasidonia, Alcalá de los Gazules, Vejer y Castellar a cambio de que éste le ayudara contra los arraeces. Pero ya indicábamos que esta afirmación resultaba problemática e interesada. No obstante, tal vez en ningún otro caso los implicados en tales estrategias dejaron tan claramente expresados sus pensamientos en torno a la virtualidad de aquella política de disolución, y en pocas ocasiones puede constatarse con tanta nitidez los comportamientos asociados a tales prácticas. Independientemente, pues, de los resultados finales, el conjunto de relaciones establecidas entre el rey de Castilla, Granada y los Banū Ašqūlūla viene a demostrar que la estrategia frente a un enemigo constituye un todo en el que se combinan elementos políticos y elementos militares, y que la historia de los fenómenos bélicos es indisociable de la historia de las pautas políticas. Así las cosas, la afirmación clausewitziana según la cual la guerra sería "la continuación de la relación política con la intrusión de otros medios", podría ser perfectamente invertida para sostener que, al menos en contextos de confrontación, las relaciones políticas vienen a ser la continuación de la guerra con la intrusión de otros medios.

\section{RÉSUMÉ}

Les dirigeants politiques du royaume de "Castilla et León" bénéficièrent souvent des problèmes de "al-Andalus". Les souverains chrétiens exploitèrent les dissidences internes de

\footnotetext{
${ }^{53}$ Sobre el enrarecimiento de las relaciones entre nazaríes y benimerines a partir de 1275 hasta su ruptura en 1277, véase IBN KHALDOUN, Histoire des Berbères, IV, pp. 79-81 y pp. 85102; IBN AL-JATīB, Kitāb A'māl ed. Allouche, pp. 5-8; IBN ABĪ ZAR', Rawd al-qirțās, pp. 596602 y pp. 605-628; $C A X$, caps. LXI-LXIII, pp. 49-50, cap. LXVII, p. 53 y caps. LXIX-LXII, pp. 53-57.
} 
l'Islam de la Péninsule et appuyèrent les rébellions contre les leaders politiques musulmans afin de les affaiblir et d'obtenir des profits territoriaux et économiques. Pendant la deuxième moitié du XIIIème siècle, Alfonso X usa de cette "stratégie politique" en encourageant la révolte des Banū Ašqīlūla tournée contre la stabilité de Granade.

\section{SUMMARY}

The political leaders of the Castilian and Leonese Kingdom often took advantage of the problems in Al-Andalus to their own benefit. The Cristian kings exploited the internal differences of Peninsular Muslims and supported the rebellions against muslim political leaders in order to weaken them and to obtain territorial and economic advantages. During the second half of the thirteenth century, Alfonso $\mathrm{X}$ applied this political strategy and supported the rebellion carried out by the Banū Ašqīlūla against the kingdom of Granada. 